\title{
Investigating the effect of information technology on strategic management: A case study of after sale services
}

\author{
Majid Farnia, Esmaeel Mohseni and Somayeh Hozouri*
}

Department of Management, Islamic Azad University, South Tehran Branch, Tehran, Iran \begin{abstract}
C H R O N I C L E
Article history:

Received May 12, 2013

Received in revised format

12 September 2013

Accepted 7 October 2013

Available online

October 252013

Keywords:

Information technology

Efficiency and effectiveness

Auto industry
\end{abstract}

\section{Introduction}

Information technology (IT) plays essential role on the success of organizations; it eases the access on information, reduces time on reaching the necessary information and builds a better communication among different groups of an organization. These days, people are more concerned to do their daily activities using the recent advances of information technology (IT) such as online banking activities, ordering products, etc. During the past few years, there have been many studies on measuring the effects of information technology on improving the performance of organizations (Venkatesh et al., 2003). Davis (1989) investigated perceived usefulness, perceived ease of use, and user acceptance of information technology. Naranjo-Gil (2009), for instance, analyzed the role of top management team in the relationship between management information systems and strategic performance. They explained how the impact of management information system on strategic performance was moderated by top management team diversity.

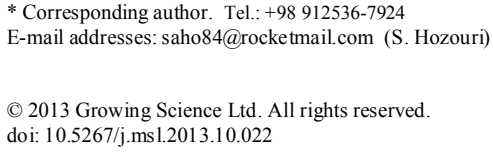


DeSarbo et al. (2008) presented a framework to integrate different perspectives of the literature on strategic and performance groups and explicitly extracted strategic/performance groups, which exhibited differences with respect to both strategy and performance, as well as display associations and potential interrelationships between the two sets of variables. They provided a new spatial technique to derive strategic/performance groups in any given industry to more completely summarize intra-industry heterogeneity.

Durmusoglu (2009) investigated how sophistication of top management view on IT infrastructure influences the firm's IT infrastructure capability and the effect of IT infrastructure capability on new product development (NPD) process outcomes such as cost, cycle time, and quality. Martinsons (2006) tried to explain the high failure rate of e-commerce ventures. The most important failure factors for e-commerce ventures were detected to include a lack of: a sound business idea, long-term planning, good market knowledge, balanced business development and external relationships. Wang et al. (2006) investigated different issues such as how technology capability influences business performance, whether the linkage between technology capability and business performance depends on specific contexts and why some high-tech firms of strong technological capability fail to reach their objectives.

Azad et al. (2014) performed an empirical investigation to detect important factors influencing information and communication technology (ICT) implementation in Iranian banking industry. The survey applied factor analysis to find important factors using a questionnaire consist of 26 variables and detected six factors influencing ICT including efficiency approach, new advanced technological achievements, human resource management, service strategy, growth strategy and supporting systems.

\section{The proposed model}

The proposed model of this paper tries to find the effect of information technology on strategic management in one of Iranian automakers. Fig. 1 demonstrates the framework of the proposed study.

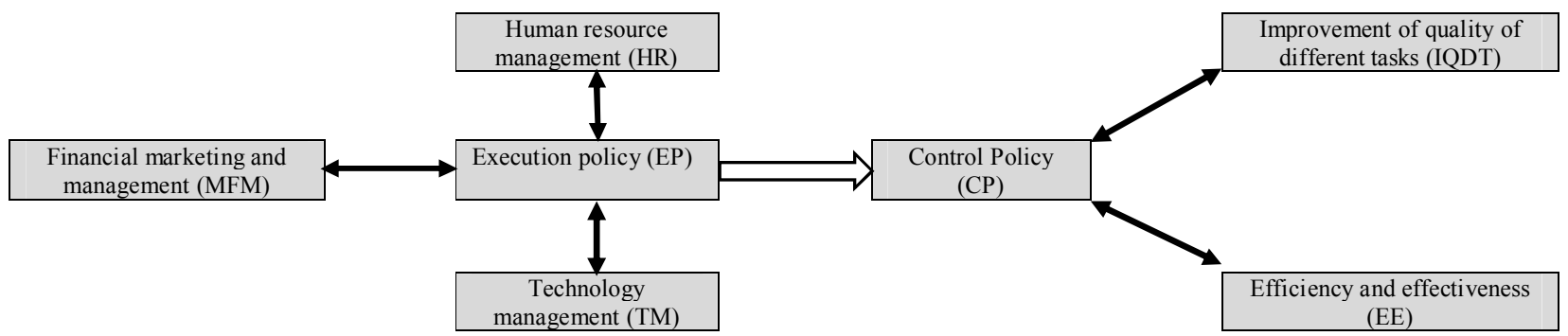

Fig. 1. The proposed model

As we can observe from the results of Fig. 1, execution policy (EP) is assumed to have some relationship with human resource management (HR) as well as technology management (TM). In addition, EP has some relationship with financial marketing and management (MFM). These relationships influence on control policy $(\mathrm{CP})$ and $\mathrm{CP}$ has relationship with improvement of quality of different tasks (IQDT) as well as efficiency and effectiveness (EE) of the system. In summary information technology (IT) in this model is considered in two phases of control and execution. The study designs a questionnaire consists of 30 questions and distributes it among some experts. Cronbach alpha has been calculated as 0.77 , which validates the overall survey. Table 1 summarizes the feedback received from the surveyed people. 
Table 1

The summary of responses to questions

\begin{tabular}{|c|c|c|c|c|c|c|c|}
\hline & Very low & Low & Average & High & Very high & Mean & Standard deviation \\
\hline Q1 & 0.00 & 4.35 & 8.70 & 71.74 & 15.22 & 3.98 & 0.65 \\
\hline Q2 & 0.00 & 15.22 & 50.00 & 28.26 & 6.52 & 3.26 & 0.80 \\
\hline Q3 & 0.00 & 4.35 & 43.48 & 47.83 & 4.35 & 3.52 & 0.66 \\
\hline Q4 & 0.00 & 19.57 & 30.43 & 41.30 & 8.70 & 3.39 & 0.91 \\
\hline Q5 & 4.35 & 8.70 & 41.30 & 32.61 & 13.04 & 3.41 & 0.98 \\
\hline Q6 & 2.17 & 19.57 & 47.83 & 28.26 & 2.17 & 3.09 & 0.81 \\
\hline Q7 & 0.00 & 15.22 & 30.43 & 41.30 & 13.04 & 3.52 & 0.91 \\
\hline Q8 & 0.00 & 0.00 & 8.70 & 41.30 & 50.00 & 4.41 & 0.65 \\
\hline Q9 & 0.00 & 4.35 & 10.87 & 43.48 & 41.30 & 4.22 & 0.81 \\
\hline Q10 & 0.00 & 10.87 & 28.26 & 41.30 & 19.57 & 3.70 & 0.92 \\
\hline Q11 & 0.00 & 2.17 & 19.57 & 43.48 & 34.78 & 4.11 & 0.80 \\
\hline Q12 & 4.35 & 28.26 & 19.57 & 34.78 & 13.04 & 3.24 & 1.14 \\
\hline Q13 & 0.00 & 2.17 & 21.74 & 39.13 & 36.96 & 4.11 & 0.82 \\
\hline Q14 & 0.00 & 0.00 & 8.70 & 56.52 & 34.78 & 4.26 & 0.61 \\
\hline Q15 & 2.17 & 17.39 & 17.39 & 36.96 & 26.09 & 3.67 & 1.12 \\
\hline Q16 & 0.00 & 2.17 & 13.04 & 52.17 & 32.61 & 4.15 & 0.73 \\
\hline Q17 & 0.00 & 2.17 & 17.39 & 56.52 & 23.91 & 4.02 & 0.71 \\
\hline Q18 & 2.17 & 17.39 & 23.91 & 52.17 & 4.35 & 3.39 & 0.91 \\
\hline Q19 & 0.00 & 4.35 & 15.22 & 65.22 & 15.22 & 3.91 & 0.69 \\
\hline Q20 & 0.00 & 0.00 & 39.13 & 34.78 & 26.09 & 3.87 & 0.81 \\
\hline Q21 & 0.00 & 0.00 & 30.43 & 60.87 & 8.70 & 3.78 & 0.59 \\
\hline Q22 & 2.17 & 28.26 & 28.26 & 41.30 & 0.00 & 3.09 & 0.89 \\
\hline Q23 & 4.35 & 10.87 & 32.61 & 34.78 & 17.39 & 3.50 & 1.05 \\
\hline Q24 & 0.00 & 15.22 & 21.74 & 58.70 & 4.35 & 3.52 & 0.81 \\
\hline Q25 & 0.00 & 8.70 & 26.09 & 56.52 & 8.70 & 3.65 & 0.77 \\
\hline Q26 & 0.00 & 4.35 & 32.61 & 43.48 & 19.57 & 3.78 & 0.81 \\
\hline Q27 & 0.00 & 13.04 & 26.09 & 36.96 & 23.91 & 3.72 & 0.98 \\
\hline Q28 & 0.00 & 0.00 & 19.57 & 58.70 & 21.74 & 4.02 & 0.65 \\
\hline Q29 & 0.00 & 2.17 & 21.74 & 50.00 & 26.09 & 4.00 & 0.76 \\
\hline Q30 & 0.00 & 4.35 & 17.39 & 50.00 & 28.26 & 4.02 & 0.80 \\
\hline
\end{tabular}

Next, we present details of our findings on testing the effects of information technology on various factors shown in Fig. 1.

\section{The results}

In this section, we present details of our findings on testing various components of our survey.

\subsection{The first question: The effect of information technology on strategy execution}

The first question of the survey investigates whether information technology has any influences on strategy execution in terms of different perspectives of human resources (HR), marketing and financial management (MFM), technology management (TM) and execution policy (EP). 


\subsubsection{The effect of information technology on human resources (HR)}

The first hypothesis of this survey investigates the effect of information technology on human resources in terms of strategy execution. Table 1 summarizes some basic statistics on our survey.

Table 1

The summary of some basic statistics

\begin{tabular}{ccccc}
\hline & $\mathrm{N}$ & Mean & Std. Deviation & Std. Error Mean \\
\hline HR & 46 & 3.4420 & .40554 & .05979 \\
\hline
\end{tabular}

In addition, Table 2 demonstrates the results of testing the effect of information technology on human resources. As we can observe from the results of Table 2, $t$-student is statistically significance with $\alpha=5 \%$, which means information technology influences on human resources in terms of strategy execution.

Table 2

The summary of testing the effect of information technology on human resources (Test value $=3$ )

\begin{tabular}{ccccccc}
\hline & $\mathrm{t}$ & $\mathrm{df}$ & Sig. (2-tailed) & Mean Difference & \multicolumn{2}{c}{ 95\% Confidence Interval of the Difference } \\
\cline { 5 - 8 } & 7.393 & 45 & .000 & .44203 & .3216 & Upper \\
\hline HR & & & & & .5625 \\
\hline
\end{tabular}

\subsubsection{The effect of information technology on marketing and financial management (MFM)}

The second hypothesis of this survey studies the effect of information technology on marketing and financial management in terms of strategy execution. Table 3 summarizes some basic statistics on our survey.

Table 3

The summary of some basic statistics on marketing and financial management

\begin{tabular}{ccccc}
\hline & $\mathrm{N}$ & Mean & Std. Deviation & Std. Error Mean \\
\hline MFM & 46 & 3.8659 & .59069 & .08709 \\
\hline
\end{tabular}

Besides, Table 4 shows the results of testing the effect of information technology on marketing and financial management in strategy execution. As we can observe from the results of Table 4, t-student is statistically significance with $\alpha=5 \%$, which indicates information technology influences on marketing and financial management in terms of strategy execution.

Table 4

The summary of testing the effect of information technology on marketing and financial management $($ Test value $=3)$

\begin{tabular}{ccccccc}
\hline & $\mathrm{t}$ & \multirow{2}{*}{$\mathrm{df}$} & Sig. (2-tailed) & \multirow{2}{*}{ Mean Difference } & \multicolumn{2}{c}{ 95\% Confidence Interval of the Difference } \\
\cline { 5 - 7 } & & & & & Lower & Upper \\
\hline MFM & 9.943 & 45 & .000 & .86594 & .6905 & 1.0414 \\
\hline
\end{tabular}

\subsubsection{The effect of information technology on technology management (TM)}

The third hypothesis of this survey tries to find the impact of information technology on technology management in terms of strategy execution. Table 5 shows some basic statistics on our survey. 
Table 5

The summary of some basic statistics on technology management

\begin{tabular}{ccccc}
\hline & $\mathrm{N}$ & Mean & Std. Deviation & Std. Error Mean \\
\hline TM & 46 & 4.0435 & .48610 & .07167 \\
\hline
\end{tabular}

Table 6 presents the summary of the results of testing the effect of information technology on technology management. According to the results of Table 6, t-student is statistically significance with $\alpha=5 \%$, which means information technology influences on technology management in terms of strategy execution.

Table 6

The summary of testing the effect of information technology on technology management (Test value $=3$ )

\begin{tabular}{ccccccc}
\hline & $\mathrm{t}$ & $\mathrm{df}$ & \multirow{2}{*}{ Sig. (2-tailed) } & \multirow{2}{*}{ Mean Difference } & \multicolumn{2}{c}{$95 \%$ Confidence Interval of the Difference } \\
\cline { 5 - 7 } & & & & & Lower & Upper \\
\hline $\mathrm{TM}$ & 14.559 & 45 & .000 & 1.04348 & .8991 & 1.1878 \\
\hline
\end{tabular}

\subsubsection{The effect of information technology on execution policy (EP)}

The fourth hypothesis of this survey tries to find the effect of information technology on execution policy. Table 7 presents some basic statistics on our survey.

Table 7

The summary of some basic statistics on execution policy

\begin{tabular}{ccccc}
\hline & $\mathrm{N}$ & Mean & Std. Deviation & Std. Error Mean \\
\hline EP & 46 & 3.7838 & .38117 & .05620 \\
\hline
\end{tabular}

Table 8 presents the summary of the results of testing the effect of information technology on execution policy. According to the results of Table 8, t-student is statistically significance with $\alpha=5 \%$, which means information technology has some positive impact on execution policy.

Table 8

The summary of testing the effect of information technology on execution policy (Test value $=3$ )

\begin{tabular}{ccccccc}
\hline & \multirow{2}{*}{$\mathrm{t}$} & $\mathrm{df}$ & \multirow{2}{*}{ Sig. (2-tailed) } & \multirow{2}{*}{ Mean Difference } & \multicolumn{2}{c}{$95 \%$ Confidence Interval of the Difference } \\
\cline { 5 - 7 } & & & & & Lower & Upper \\
\hline EP & 13.947 & 45 & .000 & .78382 & .6706 & .8970 \\
\hline
\end{tabular}

\subsection{The effect of information technology on control policy}

The second question of the survey investigates the effect of information technology has any influences on control strategy in terms of various perspectives of improvement on quality of different tasks (IQDT) and effectiveness and efficiency (EE).

\subsubsection{The effect of information technology on improvement on quality of different tasks (IQDT)}

The first hypothesis of this part of the survey attempts to find the effect of information technology on improvement on quality of different tasks (IQDT). Table 9 presents some basic statistics on our survey. 
Table 9

The summary of some basic statistics

\begin{tabular}{ccccc}
\hline & $\mathrm{N}$ & Mean & Std. Deviation & Std. Error Mean \\
\hline TM & 46 & 4.0435 & .48610 & .07167 \\
\hline
\end{tabular}

Table 10 presents the summary of the results of testing the effect of information technology on improvement on quality of different tasks (IQDT). Based on the results of Table 10, t-student is statistically significance with $\alpha=5 \%$, which means information technology has some positive impact on execution policy.

Table 10

The summary of testing the effect of improvement on quality of different tasks (IQDT) (Test value $=3$ )

\begin{tabular}{|c|c|c|c|c|c|c|}
\hline & \multirow{2}{*}{$\mathrm{t}$} & \multirow{2}{*}{ df } & \multirow{2}{*}{ Sig. (2-tailed) } & \multirow{2}{*}{ Mean Difference } & \multicolumn{2}{|c|}{$95 \%$ Confidence Interval of the Difference } \\
\hline & & & & & Lower & Upper \\
\hline TM & 14.559 & 45 & .000 & 1.04348 & .8991 & 1.1878 \\
\hline
\end{tabular}

\subsubsection{The effect of information technology on efficiency and effectiveness}

The second hypothesis of this part of the survey attempts to detect the impact of information technology on efficiency and effectiveness. Table 11 presents some basic statistics on our survey.

Table 11

The summary of some basic statistics

\begin{tabular}{ccccc}
\hline & $\mathrm{N}$ & Mean & Std. Deviation & Std. Error Mean \\
\hline TM & 46 & 4.0435 & .48610 & .07167 \\
\hline
\end{tabular}

Table 12 presents the summary of the results of testing the effect of information technology on efficiency and effectiveness (EE). Based on the results of Table 12, t-student is statistically significance with $\alpha=5 \%$, which means information technology has some positive impact on efficiency and effectiveness.

Table 12

The summary of testing the effect of improvement on efficiency and effectiveness (Test value $=3$ )

\begin{tabular}{|c|c|c|c|c|c|c|}
\hline & \multirow{2}{*}{$\mathrm{t}$} & \multirow{2}{*}{ df } & \multirow{2}{*}{ Sig. (2-tailed) } & \multirow{2}{*}{ Mean Difference } & \multicolumn{2}{|c|}{$95 \%$ Confidence Interval of the Difference } \\
\hline & & & & & Lower & Upper \\
\hline EE & 11.783 & 45 & .000 & .81677 & .6772 & .9564 \\
\hline
\end{tabular}

\subsubsection{The effect of information technology on control policy $(C P)$}

The third hypothesis of this part of the survey attempts to detect the effect of information technology on control policy. Table 13 presents some basic statistics on our survey.

Table 13

The summary of some basic statistics

\begin{tabular}{ccccc}
\hline & $\mathrm{N}$ & Mean & Std. Deviation & Std. Error Mean \\
\hline $\mathrm{CP}$ & 46 & 3.7037 & .37530 & .05533 \\
\hline
\end{tabular}

Table 14 presents the summary of the results of testing the effect of information technology on policy control (PC). Based on the results of Table 14, t-student is statistically significance with $\alpha=5 \%$, which means information technology has some positive impact on policy control. 
Table 14

The summary of testing the effect of improvement on policy control (Test value $=3$ )

\begin{tabular}{ccccccc}
\hline & \multirow{2}{*}{$\mathrm{t}$} & $\mathrm{df}$ & Sig. (2-tailed) & \multirow{2}{*}{ Mean Difference } & \multicolumn{2}{c}{ 95\% Confidence Interval of the Difference } \\
\cline { 5 - 6 } & & & & & Lower & Upper \\
\hline $\mathrm{CP}$ & 12.717 & 45 & .000 & .70367 & .5922 & .8151 \\
\hline
\end{tabular}

\section{Conclusion and discussion}

Information technology plays essential role on the success of organizations; it eases the access on information, reduces time on reaching the necessary information and builds a better communication among different groups of an organization. This paper performed an empirical investigation to find the effects of information technology on strategic management in one of Iranian automakers in after sales services in Iranian auto industry. The proposed study designed questionnaire and distributed among some experts and using t-student test examined the effect of information technology on various factors. The results have confirmed that information technology influenced on strategy execution and control policy. Table 15 and Table 16 summarize the results of the effect of information technology on various sub-components of the survey.

Table 15

The summary of different sub-components of the survey in terms of execution strategy

\begin{tabular}{lllll}
\hline \multicolumn{1}{c}{ HR } & \multicolumn{2}{c}{ MFM } & \multicolumn{2}{c}{ TM } \\
\hline Employee training & $\sqrt{ }$ Prioritizing investment & $\sqrt{ }$ & Technical preparation \\
Job satisfaction & $\sqrt{ }$ & Purchasing equipment & $\sqrt{ }$ & Optimum usage of technical documents \\
Employee capabilities & $\sqrt{ }$ & Inventory control & $\sqrt{ }$ & Communication tools \\
IT based on organizational culture & $\sqrt{ }$ Resource management & $\sqrt{ }$ Reduction in time needed to access \\
HR job involvement reduction & $\sqrt{ }$ Optimizing sales figures & $\sqrt{ }$ & Ease of access to necessary information \\
Freedom in job execution & $\sqrt{ }$ Advertisements & $\sqrt{ }$ \\
\hline
\end{tabular}

Table 16

The summary of different sub-components of the survey in terms of execution strategy

\begin{tabular}{llll}
\hline \multicolumn{1}{c}{ Improvement on quality of different tasks } & \multicolumn{2}{c}{ Efficiency and effectiveness } \\
\hline Improvement in customer & $\sqrt{ }$ & Better financial performance & Ease of managers' responsibility \\
Expediting on accomplishment & $\sqrt{ }$ & Ease of performance measurement \\
Be sure of the correctness of & $\sqrt{ }$ & Optimizing managers' responses \\
Simplifying the information & $\sqrt{ }$ & On time report & $\sqrt{ }$ \\
Reduction in organizational & $\sqrt{ }$ & Measuring efficiency of each \\
Possibility of work in distance & $\sqrt{ }$ & Measuring employees' efficiency \\
\end{tabular}

\section{Acknowledgement}

The authors would like to thank the anonymous referees for constructive comments on earlier version of this paper.

\section{References}

Azad, N., Nikanpour, M., \& Hozouri, S. (2014). An exploration study on influential factors on information and communication technology. Decision Science Letters, 3(1), 37-42.

Davis, F. D. (1989). Perceived usefulness, perceived ease of use, and user acceptance of information technology. MIS quarterly, 319-340. 
DeSarbo, W. S., Grewal, R., Hwang, H., \& Wang, Q. (2008). The simultaneous identification of strategic/performance groups and underlying dimensions for assessing an industry's competitive structure. Journal of Modelling in Management, 3(3), 220-248.

Durmusoglu, S. S. (2009). The role of top management team's information technology (IT) infrastructure view on new product development: Conceptualizing IT infrastructure capability as a mediator. European Journal of Innovation Management, 12(3), 364-385.

Martinsons, M. G. (2006). Strategic management lessons from e-commerce.Handbook of Business Strategy, 7(1), 337-340.

Naranjo-Gil, D. (2009). Management information systems and strategic performances: The role of top team composition. International Journal of Information Management, 29(2), 104-110.

Venkatesh, V., Morris, M. G., Davis, G. B., \& Davis, F. D. (2003). User acceptance of information technology: Toward a unified view. MIS quarterly, 425-478.

Wang, Y., Lo, H. P., Zhang, Q., \& Xue, Y. (2006). How technological capability influences business performance: an integrated framework based on the contingency approach. Journal of Technology Management in China, 1(1), 27-52. 